\title{
KELAYAKAN FINANSIAL USAHA TEPUNG DAUN KELOR DI CV. PUSAKA MADURA DESA PAKANDANGAN SANGRAH KECAMATAN BLUTO KABUPATEN SUMENEP
}

\author{
Ribut Santosa' ${ }^{1)}$ dan Khoiratul Imamah ${ }^{2)}$ \\ 1)Prodi Agribisnis, Alumni Fakultas Pertanian Universitas Wiraraja \\ ${ }^{2)}$ Alumni Prodi Agribisnis, Fakultas Pertanian Universitas Wiraraja
}

\begin{abstract}
Abstrak
Tepung daun kelor adalah tepung hasil dari penggilingan daun kelor yang di keringkan. Tepung daun kelor bisa di jadikan bahan baku pembuatan kue-kue, nugget dan bubur sebagaimana juga sama halnya dengan tepung terigu maupun tepung tapioka. Sehingga dengan kenyataan ini, tanaman kelor sangat memiliki prospek yang cukup bagus kedepannya, khususnya di Kabupaten Sumenep yang sangat berpotensi untuk dikembangkannya usaha tersebut. Lokasi pada penelitian ini dilakukan secara (purposive) atau sengaja yaitu di CV. Pusaka Madura di Desa Pekandangan Sangrah Kecamatan Bluto Kabupaten Sumenep. Tujuan penelitian. Untuk mengetahui tingkat kelayakan finansial dan pengaruh sensitivitas usaha tepung daun kelor di Desa Pekandangan Sangrah Kecamatan Bluto Kabupaten Sumenep jika terjadi kenaikan harga bahan baku sebesar $10 \%$. Analisis data pada penelitian ini menggunakan analisis kelayakan finansial. kriteria investasi yang akan digunakan adalah NPV, Net B/C. IRR, PP dan Sensivitas 10\%. Hasil penelitian menunjukkan bahwa nilai NPV sebesar Rp. 15.499.300; Net B/C sebesar 4,85; IRR sebesar 48\% dan PP nya dengan jangka waktu 2,86 tahun ( 2 tahun 10 bulan 10 hari). Hasil tersebut dapat disimpukan bahwa usaha tepung daun kelor di CV. Pusaka Madura menguntungkan dan layak dikembangkan. Selain itu, hasil dari analisis sensitivitas dengan kenaikan harga bahan baku daun kelor sebesar 10\% diperoleh nilai NPV sebesar Rp. 12.684.722; Net B/C sebesar 4,27; IRR sebesar 44\% dan PP nya dalam jangka waktu 3 tahun 4 bulan 10 hari. Sehingga usaha tepung daun kelor di CV. Pusaka Madura masih layak untuk diusahakan.
\end{abstract}

Kata kunci: Kelayakan Finansial, Tepung Daun Kelor

\section{PENDAHULUAN}

Daun kelor (moringa oleifera lamk) merupakan salah satu komoditas holtikultura yang banyak memiliki manfaat karena hampir semua bagian dari tanaman kelor dapat bermanfaat untuk kehidupan manusia dan menjadi sumber makanan karena mengandung senyawa aktif dan gizi lengkap (Anwar, 2007).

Selain kandungan vitamin A dan

C serta senyawa aktif lainnya ternyata daun kelor juga mengandung zat besi, kalsium, fosfor, karbohidrat dan serat sehinnga tidak salah masyarakat di kawasan asia dan afrika 
menjulukinya sebagai miracle tree (pohon ajaib).

Sejak zaman nenek moyvang kita hingga sekarang kelor biasa di manfaatkan untuk berbagai kebutuhan seperti pengobatan tradisional, pelengkap hidangan dan juga banyak digunakan sebagai pagar rumah disenfektan. Seiring meningkatnya taraf ekonomi, berkembangnya teknologi dan kesadaran masyarakat Indonesia untuk mengkonsumsi makanan sehat alami, kini daun kelor yang biasanya hanya di jadikan sebagai tanaman pagar oleh orang-orang desa dan hanya dijadikan $\mathrm{s}$ peleyuran pelengkap saat makan, kini kelor sudah merambat merubah manfaat dan memiliki nilai tambah. Salah satu hasil pengolahan usaha yang dapat dikembangkan dari daun kelor yaitu tepung daun kelor.

Tepung daun kelor adalah tepung hasil dari penggilingan daun kelor yang di keringkan. Tepung daun kelor bisa di jadikan bahan baku pembuatan kue-kue, nugget dan bubur sebagaimana juga sama halnya dengan tepung terigu maupun tepung tapioka. Sehingga dengan kenyataan ini, tanaman kelor sangat memiliki prospek yang cukup bagus kedepannya, khususnya di kabupaten sumenep yang sangat berpotensi untuk dikembangkannya usaha tersebut.

CV. Pusaka Madura menjadi wadah bagi masyarakat Desa pekandangan Sangrah melakukan proses pengolahan daun kelor. Salah satu produk lokal yang sudah beredar luas dipasaran diantaranya adalah tepung daun kelor dan teh daun kelor.

Berdasarkan uraian di atas maka yang menjadi tujuan penelitian ini adalah untuk mengetahui tingkat kelayakan finansial dan pengaruh sensitivitas usaha tepung daun kelor di Desa Pekandangan Sangrah Kecamatan Bluto Kabupaten Sumenep jika terjadi kenaikan harga bahan baku sebesar $10 \%$.

\section{METODE PENELITIAN}

Penelitian ini dilakukan secara (purposive) yaitu di CV. Pusaka Madura di Desa Pekandangan Sangrah Kecamatan Bluto Kabupaten Sumenep dengan pertimbangan bahwa CV. Pusaka Madura adalah satu-satunya CV. yang mengembangkan usaha dalam bidang pengolahan usaha daun kelor.

Analisis data menggunakan analisis kelayakan finansial. Kriteria investasi yang akan digunakan sebagai berikut :

A. Analisis net present value (NPV).

Net present value (NPV) adalah selisih antara present value dari pada benefit dan present value dari pada biaya. Untuk menghasilkan NPV kita akan mendapatkannya dari selisih cash in flow dengan cash out flow yang biasa terjadi di setiap tahun dan disebut net benefit. Untuk 
menghasilkan present value maka net benefit di discounted dengan opportunity cost of capital yang berlaku secara umum, dari net benefit maka akan kita ketahui NPVnya, dengan arti lain NPV bisa dikatakan penerimaan dikurangi kesuluruhan biaya yang digunakan dalam proses produksi menghasilkan net benefit atau kerugian, kemudian dikalikan dengan suku bunga yang berlaku dan menghasilkan NPV, dengan kriteria :

Apabila NPV> 0 maka usaha tepung daun kelor layak di kembangkan

Apabila NPV $<0$ maka usaha tepung daun kelor tidak layak di kembangkan / rugi

Apabila NPV $=0$ maka usaha tepung daun kelor tidak untung tidak rugi ( impas).

\section{B. Analisis $N e t B / C$}

Net $B / C$ adalah alat analisis yang di gunakan untuk mengukur besaran keuntungan atau kerugian dan kelayakan usaha atau proyek yang akan dilaksanakan. Net B/C ini bermanfaat untuk mengetahui perhitungan biaya dan benefit yang akan diperoleh dalam pelaksanaan usaha atau proyek. Dalam analisis ini benefit serta perhitungan biaya merupakan satu kesatuan yang tidak dapat di pisahkan. Adapun kriteria yang dipakai pada analisa Net B/C ini adalah apabila Net B/C > 1 berarti proyek tersebut memberikan manfaat, sedangkan apabila Net B/C
$<1$ berarti proyek tersebut tidak memberikan manfaat.

$$
\begin{gathered}
\text { Net } \quad \mathbf{B} / \mathbf{C} \\
\frac{\sum_{t=1}^{n} \frac{B t-C t}{(1+i)^{t}}\left(B_{t}-C_{t}>0\right)}{\sum_{t=1}^{n} \frac{B t-C t}{(1+i)^{t}}\left(B_{t}-C_{t}<0\right)} \\
\text { dimana : } \\
\text { Bt }=\text { besarnya benefit } \\
\text { finansial } \quad \text { besarnya biaya } \\
\text { finansial } \quad \\
\mathrm{i}=\text { sosial discount rate }(\%) \\
\mathrm{n}=\text { umur ekonomis }
\end{gathered}
$$

C. Analisis internal rate of retune (IRR)

Analisis ini untuk melihat kemampunan investasi yang dikeluarkan untuk suatu tingkat keuntungan yang didapat berdasarkan tingkat bunga pinjaman (opportunity cost of capital). IRR adalah nilai discount rate yang membuat NPV daripada proyek sama dengan 0 .

Kriteria pengambilan keputusan:

a. IRR > bunga modal, usaha tepung daun kelor layak untuk diusahakan dan menguntungkan.

b. IRR < bunga modal, usaha tepung daun kelor tidak layak untuk diusahakan dan menguntungkan. 
D. Payback periode (PP)

Payback periode merupakan analisis suatu jangka waktu (periode) kembalinya keseluruhan investasi kapital yang ditanam. Semakin cepat waktu pengembalian modal maka akan semakin baik usaha tersebut dikembangkan.

Adapun rumus yang di gunakan dalam payback periode :

$$
\mathrm{PP}=\text { Total Nilai Investasi }
$$

$$
\text { Arus Kas Pertahun }
$$

E.Analisis sensitivitas (Switching value)

Analisis sensitivitas ini di perlukan karena dalam kegiatan investasi, perhitungan didasarkan pada proyek-proyek yang mengandung ketidakpastian (berubah - ubah) tentang apa yang akan terjadi di waktu yang akan datang (Gittenger, 1986).

Empat masalah utama yang mengakibatkan perubahan tersebut biasanya dari harga jual produk, kenaikan biaya perubahan volume produksi dan keterlambatan pelaksanaan proyek sehingga analisis switching value perlu di gunakan untuk mengetahui seberapa besar penurunan harga atau kenaikan biaya yang terjadi dapat mengakibatkan perubahan dalam kelayakan investasi dari layak menjadi tidak layak. Tujuan analisis ini adalah untuk melihat kembali hasil analisis suatu kegiatan investasi atau aktivitas ekonomi, apakah ada perubahan dan terjadi kesalahan atau ada perubahan di dalam perhitungan biaya atau manfaat (Nurmalina Et Al., 2009).

\section{HASIL DAN PEMBAHASAN Komponen dan Struktur Biaya Biaya Investasi}

Biaya investasi merpakan biaya yang dikeluarkan untuk pengadaan peralatan usaha tepung daun kelor dan memiliki nilai penyusutan. Berikut merupakan biaya investasi yang disajikan pada Tabel 4.1

Tabel 4.1, Biaya investasi usaha tepung daun kelor di CV. Pusaka Madura sebesar Rp. 87.435.000. Biaya investasi investasi terbesar adalah biaya gudang sebesar Rp 50.000 .000 (57,18\%), selama 10 tahun. Biaya Investasi atau cash flow terdapat pada Lampiran 5.

\section{Biaya Penyusutan}

Biaya peralatan memiliki nilai ekonomis yang berbeda sesuai dengan kemampuan yang dimiliki barang tersebut. Nilai ekonomis akan berkurang seiring dengan penggunaan barang tersebut, hal inilah yang disebut biaya penyusutan. Biaya penyusutan sebagai biaya pengganti nilai ekonomis barang yang hilang. Adapun biaya penyusutan dalam usaha tepung daun kelor di CV. Pusaka Madura tersaji pada Tabel 4.2. 
Tabel 4.1. Biaya Investasi Usaha Tepung Daun Kelor di CV. Pusaka Madura

\begin{tabular}{lrc}
\hline \multicolumn{1}{c}{ Biaya Investasi } & \multicolumn{1}{c}{$\begin{array}{c}\text { Nilai } \\
(\mathbf{R p})\end{array}$} & $\begin{array}{c}\text { Persentase } \\
(\mathbf{\%})\end{array}$ \\
\hline Rak Pengering & 15.000 .000 & 17,16 \\
Lampu Pemanas & 750.000 & 0,86 \\
Kipas Tornado & 2.400 .000 & 2,74 \\
Kipas Angin Horizontal & 1.500 .000 & 1,72 \\
Ekhos Fan & 650.000 & 0,74 \\
Mesin (BSD 200) & 6.950 .000 & 7,95 \\
Seller Motor & 175.000 & 0,20 \\
Part Printing & 1.060 .000 & 1,21 \\
Box Konteiner & 4.000 .000 & 4,58 \\
Mesin Penggiling & 4.950 .000 & 5,66 \\
Gudang & 50.000 .000 & 57,18 \\
\hline Jumlah Biaya Investasi & $\mathbf{8 7 . 4 3 5 . 0 0 0}$ & $\mathbf{1 0 0 , 0 0}$ \\
\hline
\end{tabular}

Sumber: Data Primer yang Diolah, 2018

Tabel 4.2. Biaya Penyusutan Usaha Tepung Daun Kelor CV. Pusaka Madura

\begin{tabular}{lrr}
\hline \multicolumn{1}{c}{ Alat Produksi } & Biaya Penyusutan & $\begin{array}{c}\text { Persentase } \\
(\mathbf{\%})\end{array}$ \\
\hline Rak Pengering & 1.875 .000 & 20,66 \\
Lampu Pemanas & 246.667 & 2,72 \\
Kipas Tornado & 470.000 & 5,18 \\
Kipas Angin Horizontal & 362.500 & 3,99 \\
Ekhos Fan & 115.000 & 1,27 \\
Mesin (BSD 200) & 681.250 & 7,51 \\
Seller Motor & 31.000 & 0,34 \\
Part Printing & 107.500 & 1,18 \\
Box Konteiner & 790.000 & 8,71 \\
Mesin Penggiling & 395.000 & 4,35 \\
Gudang & 4.000 .000 & 44,08 \\
\hline \multicolumn{1}{c}{ Jumlah Biaya } \\
\multicolumn{1}{c}{ Penyusutan } & $\mathbf{9 . 0 7 3 . 9 1 7}$ & $\mathbf{1 0 0 , 0 0}$ \\
\hline
\end{tabular}

Sumber: Data Primer yang Diolah, 2018

Tabel 4.2, diketahui bahwa jumlah biaya penyusutan usaha tepung daun kelor di CV. Pusaka Madura sebesar Rp. 9.073.917. Biaya penyusutan terbesar adalah biaya gudang sebesar Rp. 4.000.000 (44,08\%) per tahun.

\section{Kriteria Kelayakan Investasi}

Penghitungan analisis financial dapat menggunakan criteria kelayakan investasi. Kriteria kelayakan investasi digunakan untuk mengetahui atau mengukur manfaat yang diperoleh dan biaya yang dikeluarkan dalam usaha tepung daun kelor. Berdasarkan kriteria 
kelayakan investasi, maka dapat diketahui apakah usaha tepung daun kelor di CV. Pusaka Madura layak diusahakan atau tidak. Analisis criteria investasi yang digunakan yakni, NPV (net present value), Net
$\mathrm{B} / \mathrm{C}$, IRR (internal rate return), $\mathrm{PP}$ (payback periods), dan sensivitas. Hasil analisis kriteria investasi disajikan pada Tabel 4.3.

Tabel 4.3. Hasil Analisis Kriteria Kelayakan Investasi dalam Usaha Tepung Daun Kelor di CV. Pusaka Madura

\begin{tabular}{lcl}
\hline \multicolumn{1}{c}{ Kriteria Investasi } & Hasil Analisis & \multicolumn{1}{c}{ Keterangan } \\
\hline NPV (Net Present Value) & 15.499 .300 & Layak \\
Net B/C & 4,85 & Bermanfaat \\
IRR (Internal Rute Return) & $48 \%$ & Layak dan Menguntungkan \\
PP (Payback Periods) & 2 tahun 10 bulan 10 hari & Layak \\
\hline Sumber: Data Primer yang Diolah, 2018 &
\end{tabular}

Tabel 4.4. Analisis Sensitivitas Switching Value dengan Kenaikan Bahan Baku Daun Kelor Sebesar 10\%

\begin{tabular}{lcl}
\hline \multicolumn{1}{c}{ Kriteria Investasi } & Hasil Analisis & \multicolumn{1}{c}{ Keterangan } \\
\hline NPV (Net Present Value) & 12.684 .722 & Layak \\
Net B/C & 4,27 & Bermanfaat \\
IRR (Internal Rute Return) & $44 \%$ & Layak dan Menguntungkan \\
PP (Payback Periods) & 3 tahun 4 bulan 10 hari & Layak \\
\hline Sumber: Data Primer yang Diolah, 2018. &
\end{tabular}

Berdasarkan Tabel 4.3, maka dapat dijelaskan sebagai berikut:

\section{a. NPV (Net Present Value)}

Nilai NPV usaha tepung daun kelor di CV. Pusaka Madura pada tingkat suku bunga $9,96 \%$ sebesar Rp. 15.499.300. Hal ini menunjukkan bahwa nilai NPV lebih besar dari pada nilai nol atau bernilai positif, maka usaha tepung daun kelor di CV. Pusaka Madura layak diusahakan.

b. Net B/C

Nilai Net B/C pada usaha tepung daun kelor sebesar 4,85.
Nilai Net B/C $(4,85)$ lebih besar dari pada 0. Artinya, setiap Rp. 1 biaya yang dikeluarkan dapat menghasilkan Rp 4,85. Maka, dapat disimpulkan bahwa usaha tepung daun kelor di CV. Pusaka Madura memberikan manfaat atau menguntungkan.

c. IRR (Internal Rate Return) IRR merupakan salah satu kriteria investasi yang digunakan untuk mengetahui seberapa besar tingkat pengembalian investasi yang ditanamkan usaha tepung daun kelor di CV. Pusaka Madura yang 
diukur dengan suku bunga yang berlaku yaitu $9,96 \%$. Nilai IRR sebesar $48 \%$, hal ini menunjukkan bahwa nilai IRR lebih besar dari tingkat suku bunga yang berlaku $(48 \%>9,96 \%)$. Artinya, usaha tepung daun kelor di CV. Pusaka Madura layak untuk dijalankan. Selain itu, nilai $I R R$ tersebut juga menunjukkan bahwa tepung daun kelor di CV. Pusaka Madura akan tetap layak untuk diusahakan hingga tingkat suku bunga mencapai $48 \%$.

d. PP (Payback Periods)

Nilai $P P$ yaitu sebesar 2,86 yang artinya, usaha tepung daun kelor di CV. Pusaka Madura dapat mengembalikan investasi kurun waktu 2 tahun 10 bulan 10 hari yang dilakukan dengan perhitungan kelayakan berdasarkan periode proyek 10 tahun.

\section{e. Sensitivitas Switching Value}

Suatu usaha dalam pengelolaan produksi tidak akan lepas dari adanya suatu perubahan khususnya pada biaya produksi, sebab harga bahan-bahan yang digunakan dalam pembuatan tepung daun kelor akan mengalami kenaikan atau penurunan diakibatkan oleh permintaan pasar. Analisis sensitivitas digunakan untuk mengetahui seberapa besar pengaruh jika terjadi kenaikan harga bahan baku daun kelor sebesar 10\%. Adapun kriteria kelayakan investasi usaha tepung daun kelor di CV. Pusaka Madura dengan kenaikan bahan baku sebesar $10 \%$ dapat dilihat pada Tabel 4.4.
Tabel 4.4, menunjukkan bahwa pada saat bahan baku daun kelor yang digunakan dalam usaha tepung daun kelor mengalami kenaikan harga sebesar 10\%, maka nilai NPV mengalami penurunan menjadi $\mathrm{Rp}$. 12.684.722, Net B/C turun menjadi 4,27, dan nilai IRR menjadi $44 \%$, serta nilai PP semakin lama yaitu menjadi 3 tahun 4 bulan 10 hari. Dalam kondisi ini usaha tepung daun kelor di CV. Pusaka Madura masih layak dikusahakan.

\section{KESIMPULAN DAN SARAN}

\section{Kesimpulan}

Hasil perhitungan analisis kelayakan yang telah dilakukan diperoleh nilai NPV sebesar Rp. 15.499.300; Net $\mathrm{B} / \mathrm{C}$ sebesar 4,85; IRR sebesar $48 \%$ dan PP nya dengan jangka waktu 2,86 tahun (2tahun 10 bulan 10 hari). Berdasarkan hasil tersebut dapat disimpukan bahwa usaha tepung daun kelor di CV. Pusaka Madura menguntungkan dan layak dikembangkan. Hasil analisis sensitivitas dengan kenaikan harga bahan baku daun kelor sebesar $10 \%$ maka diperoleh nilai NPV sebesar Rp. 12.684.722; Net B/C sebesar 4,27; IRR sebesar 44\% dan PP nya dalam jangka waktu 3 tahun 4 bulan 10 hari. Sehingga usaha tepung daun kelor di CV. Pusaka Madura masih layak untuk diusahakan. 
Saran

Berdasarkan hasil penelitian maka terdapat beberapa saran yang diajukan terhadap usaha tepung daun kelor di CV. Pusaka Madura yaitu meningkatkan jumlah produksi agar permintaan pasar terpenuhi dan penelitian ini dapat dijadikan referensi bagi peneliti selanjutnya yang berkaitan dengan penelitian ini.

\section{DAFTAR PUSTAKA}

Aditya Nugraha, 2013. Bioaktivitas Ekstrak Daun Kelor (Moringa Oleifera) Terhadap Eschericia Coli Penyebab Kolibasilosis Pada Babi. Program Studi Kedokteran Hewan Program Pascasarjana Universitas Udayana Denpasar.

Anwar, F., Latif, S., Ashraf, M., Gilani, A.H., 2007. Moringa oleifera: a food plant with multiple medicinal uses. Phytother. Res. 21, $17-25$

Downey, W. David dan Erickson, Steven P. 2001. Manajemen Agribisnis. Erlangga. Jakarta.

Gittinger, J.P. 1986. Analisa ProyekProyek Pertanian. Edisi Kedua. Jakarta: Universitas Indonesia.

Husnan, S dan Suswarno, 2000. Studi Kelaykan Proyek. Edisi ke-4. UPP. AMD. YKPN. Yogyakarta.

Kadariah, L. Karlina dan C. Gray. 1986. Evaluasi Proyek. Analisis Ekonomis. LPFE. UI. Jakarta
Kartasapoetra, G. 2000. Manajemen Penanaman Modal Asing, Bina Aksara, Bandung.

Mubyarto. 1986. Pengantar Ekonomi Pertanian. LP3BS. Jakarta.

Rudianto, Syam, A dan Alharni, S. 2009. Studi Pembuatan dan Analisis Zat Gizi Pada Produk Biskuit Moringa Oleifera Dengan Subtitusi Tepung Daun Kelor. Program Studi Ilmu Gizi Fakultas Kesehatan Masyarakat Universitas Hasanuddin.

http://repository.unhas.ac.id/bitstre am/handle/123456789/11378/RUD IANTO\%20K21110308.pdf?seque nce=1 /Akses 25 Januari 2017.

Theodorus M. Tuanakotta, 2000. Pernyataan Standar Akuntansi Keuangan. Jakarta : Penerbit Salemba Empat

Umar. H. 2005. Study Kelayakan Edisi 3. Terbitan. Gramedia Pusaka Utama. Jakarta

Zakaria, Tamrin, A., Sirajudin, dan Hartono, R., 2012. Penambahan Tepung Daun Kelor Pada Menu Makanan SehariHari Dalam Upaya Penanggulangan Gizi Kurang Pada Anak Balita Jurusan Gizi Poltekkes Kesehatan Kemenkes. Makassar. https://jurnalmediagizipangan.files.wordpr ess.com/2012/07/Di Akses 25 Januari 2017 
